\title{
A Novel Cyclopentene Derivative and a Polyhydroxylated Steroid from a South China Sea Gorgonian Menella sp.
}

\author{
Xing-Yun ChaI, ${ }^{a}$ Jian-Fan Sun, ${ }^{a}$ Li-Ying TAng,${ }^{b}$ Xian-Wen YAng,${ }^{a}$ Yun-Qiu Li, ${ }^{a}$ Hui Huang,,${ }^{a, c}$ \\ Xue-Feng ZHOU, ${ }^{a}$ Bin YAnG, ${ }^{a}$ and Yonghong LiU ${ }^{*}, a$ \\ ${ }^{a}$ Key Laboratory of Marine Bio-resources Sustainable Utilization/Guangdong Key Laboratory of Marine Materia \\ Medica/Research Center for Marine Microbes, South China Sea Institute of Oceanology, Chinese Academy of Sciences; \\ Guangzhou 510301, China: ${ }^{b}$ Institute of Traditional Chinese Materia Medica, Chinese Academy of Medical Sciences; \\ Beijing 100700, P. R. China: and ${ }^{c}$ National Experiment Station of Tropical Marine Biology; Sanya 572000, China. \\ Received February 5, 2010; accepted July 13, 2010; published online July 29, 2010
}

\begin{abstract}
A chemical investigation on a South China Sea gorgonian, Menella sp. resulted in the isolation and elucidation of menellin A (1), a highly oxygenated racemate with $\mathrm{C}_{8}$ skeleton, and a polyhydroxylated steroid, menellsteroid C (2), along with eight known compounds (3-10). The structures of the new compounds were elucidated by means of MS, 1D and 2D NMR spectra, and the relative stereochemistry of 1 was determined by X-ray singlecrystal diffraction analysis. In addition, compound 7 was isolated as a new natural product. Compounds $1-3$ and 7 were selected to test the anti-inflammatory inhibition against lipopolysaccharide (LPS)-induced nitric oxide (NO) production in RAW264.7 macrophages. 1 and 3 exhibited modest inhibitory effects with $\mathrm{IC}_{50}$ of 71.3 , 33.9 $\mu \mathrm{M}$, respectively, compared to the positive control aminoguanidine $\left(\mathrm{IC}_{\mathbf{5 0}} 25.0 \mu \mathrm{M}\right)$.
\end{abstract}

Key words Menella sp.; gorgonian; menellin A; menellsteroid C; X-ray diffraction; anti-inflammatory inhibition

Gorgonians, with trivial names of Sea Fan or Sea Whip etc., are one of the important sources recognized the new and significant biological activity of metabolites and are arousing the interest of chemists all over the world. There are a large number of papers every year on secondary metabolite research of the gorgonians. ${ }^{1-4)}$ However, one of the prolific gorgonian in the South China Sea, the Menella sp., has been given comparatively less attention, with the exception of four papers that described the guaiane sesquiterpenoids, polyhydroxylated steroids and other known compounds. ${ }^{5-8)}$

As a part of our systematic research on the structurally novel and significantly bioactive metabolites from South China Sea invertebrates, we undertook a chemical investigation on an unidentified gorgonian species Menella sp., collected on Hainan Island. This resulted in the isolation and structure elucidation of a novel constituent, we named menellin A (1), and a polyhydroxylated steroid menellsteroid C (2), together with eight known compounds (3-10), including a new natural product (7). The structures of these new compounds were elucidated by spectrum analysis of MS, 1D and 2D NMR. The relative stereochemistry of 1 was determined by X-ray single-crystal diffraction analysis.

\section{Results and Discussion}

Menellin A (1) was obtained as a colorless quadrate crystal $\left(\mathrm{CHCl}_{3}-\mathrm{MeOH}\right)$. Its molecular formula was determined as $\mathrm{C}_{11} \mathrm{H}_{14} \mathrm{O}_{8}$ by an $[\mathrm{M}-\mathrm{H}]^{-}$ion peak at $m / z 273.0618$ (Calcd 273.0616) in the high-resolution-electrospray ionization (HR-ESI)-MS, indicating 5 degrees of unsaturation. The IR spectrum exhibited the characteristic absorption for a hydroxyl $\left(3485 \mathrm{~cm}^{-1}\right)$ and carboxyls [1736, 1706 (br) $\mathrm{cm}^{-1}$ ]. The ${ }^{1} \mathrm{H}$ - and ${ }^{13} \mathrm{C}-\mathrm{NMR}$ spectra (Table 1) showed the signals for an olefin $\left[\delta_{\mathrm{H}} 6.82(\mathrm{t}, 1.5) ; \delta_{\mathrm{C}} 142.4,137.0\right]$, three methoxys $\left[\delta_{\mathrm{H}} / \delta_{\mathrm{C}} 3.78 / 53.1(9), 3.45 / 59.6(10), 3.77 / 52.5\right.$ $(11)]$, three carboxyl carbons $[\delta 173.6$ (C-8), 172.6 (C-7), 165.7 (C-6)], an oxygenated methine at $\delta 4.65 / 94.9$, and a methine at $\delta 4.21 / 58.9$, as well as an oxygenated quaternary carbon at $\delta 86.7$. These data implied 1 to be a highly oxy- genated compound with a single ring. These assignments and the planar structure were achieved by heteronuclear single quantum coherence (HSQC) and heteronuclear multiple bond coherence (HMBC) experiments. The HMBC correlations from two methoxys $(\mathrm{OMe}-9,11)$ to two carboxyls $(\mathrm{C}-8$, 6) respectively suggested the appearance of two methyl esters in the structure of $\mathbf{1}$. An HMBC correlation from H-4 $(\delta$ 6.82) to C-6 established the connection of one methyl ester with the olefin. The HMBC correlations from additional methoxy proton to $\mathrm{C}-3$, from $\mathrm{H}-3$ to the quaternary olefin carbon (C-5), C-8 and C-2, as well as from H-1 to C-7 and C-8 showed the planar structure of $\mathbf{1}$ to be a derivative of cyclopentene with three carboxyl groups attached at the ring (Fig. 1).

The relative stereochemistry of $\mathbf{1}$ was finally determined by X-ray single-crystal diffraction analysis after the failure by nuclear Overhauser effect spectroscopy (NOESY) spectrum, where no useful NOESY correlation was observed between the H-1 with H-3, or between OMe-9 with OMe-10. However, the X-ray diffraction result showed that the $\mathbf{1}$ is a natural racemate in consideration of its space group (P-1), as $\mathrm{P}-1$ is a racemic space group, one with $1 S, 2 S, 3 S$ configurations (1) and another with all $R$ configurations. This conclusion was further confirmed by the almost zero optical rota-

Table 1. The NMR Data of Compound 1

\begin{tabular}{rrc}
\hline \hline No. & $\delta_{\mathrm{C}}$ & $\delta_{\mathrm{H}}$ \\
\hline 1 & 58.9 & $4.21 \mathrm{~d}(1.5)$ \\
2 & 86.7 & - \\
3 & 94.9 & $4.65 \mathrm{br} \mathrm{s}$ \\
4 & 142.4 & $6.82 \mathrm{t}(1.5)$ \\
5 & 137.0 & - \\
6 & 165.7 & - \\
7 & 172.6 & - \\
8 & 173.6 & 3.78 \\
9 & 53.1 & 3.45 \\
10 & 59.6 & 3.77 \\
11 & 52.5 & - \\
\hline
\end{tabular}




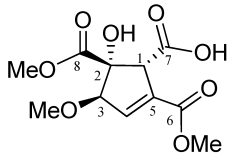

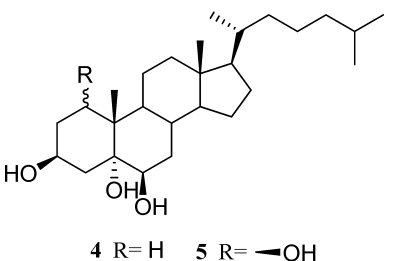

$4 \mathrm{R}=\mathrm{H} \quad 5 \mathrm{R}=-\mathrm{OH}$

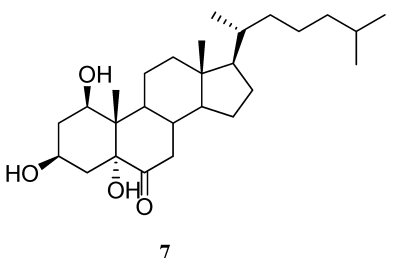

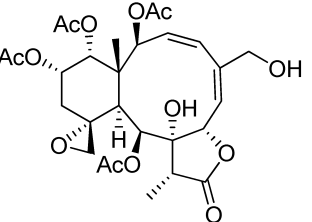

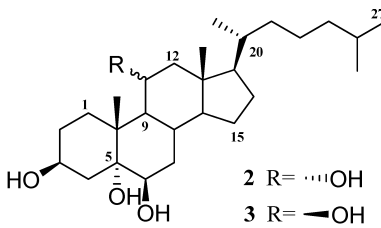
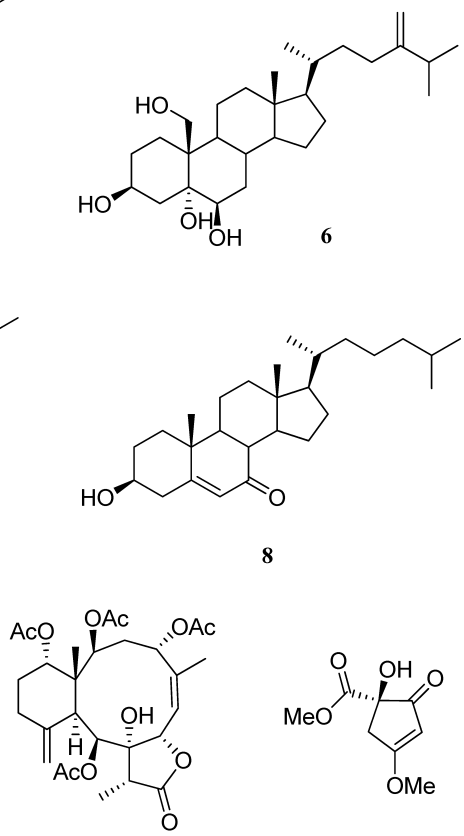

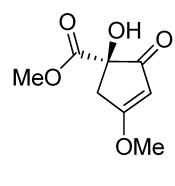

11
Fig. 1. Structures of Compounds from Menella sp. (1-10) and (+)-Kjellmanone (11) tion value.

Menellsteroid C (2) was obtained as white powder. Its molecular formula was determined as $\mathrm{C}_{27} \mathrm{H}_{48} \mathrm{O}_{4}$ by its ESI-MS ion $[\mathrm{M}+\mathrm{Na}]^{+}$at $m / z 459$ and NMR data (Table 2). The ${ }^{1} \mathrm{H}-$ and ${ }^{13} \mathrm{C}-\mathrm{NMR}$ spectra showed characteristic signals of five methyls, including two tertiary ones $(\mathrm{C}-18,19)$ and three secondary methyls at $\delta_{\mathrm{H}} / \delta_{\mathrm{C}} 0.99 / 19.2(\mathrm{C}-21), 0.89 / 22.9(\mathrm{C}-26)$ and $0.89 / 23.2$ (C-27), which in collaboration with its typical $\mathrm{C}-3$ oxygenated proton signal at $\delta_{\mathrm{H}} 4.02(\mathrm{~m}, \mathrm{H}-3)$ and one at $\delta_{\mathrm{H}} 3.46$ (brs, H-6) due to both C-5 and C-6 hydroxylated in its ${ }^{1} \mathrm{H}-\mathrm{NMR}$, suggested 2 a polydroxylated cholestan-type steroid. A detailed comparison of its NMR data with those of menellsteroid A $(3)^{7,9)}$ showed both are isomers with high structural similarity (Fig. 1), which was supported and confirmed by the HMBC spectra (Fig. 2). The differences be-
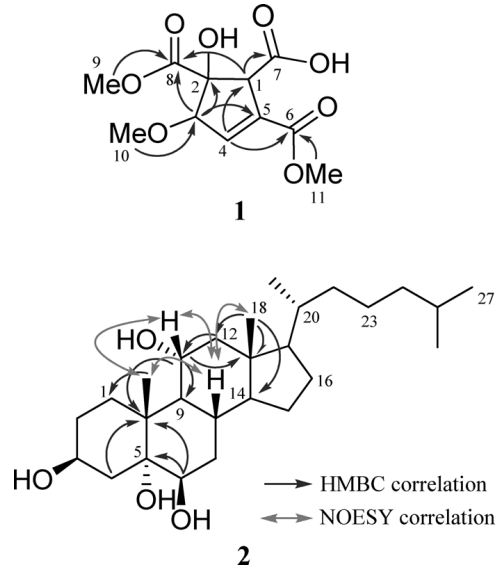

Fig. 2. Key HMBC and NOESY Correlations of $\mathbf{1}$ and $\mathbf{2}$

Table 2. NMR Data $\left(\mathrm{CD}_{3} \mathrm{OD}, 500 / 125 \mathrm{MHz}\right)$ for $\mathbf{2}, \mathbf{3}$ and $\mathbf{7}, \delta$ in ppm and $J$ in $\mathrm{Hz}$

\begin{tabular}{|c|c|c|c|c|c|}
\hline \multirow{2}{*}{ No. } & \multicolumn{2}{|l|}{2} & \multirow{2}{*}{$\frac{3}{\delta_{\mathrm{C}}}$} & \multicolumn{2}{|l|}{7} \\
\hline & $\delta_{\mathrm{H}}$ & $\delta_{\mathrm{C}}$ & & $\delta_{\mathrm{H}}$ & $\delta_{\mathrm{C}}$ \\
\hline 1 & $2.07 \mathrm{t}(11.5), 1.79 \mathrm{~m}$ & 35.4 & 33.2 & $4.07 \mathrm{dd}(10.5,5.5)$ & 71.7 \\
\hline 2 & $1.78,1.53$ each $\mathrm{m}$ & 32.0 & 31.6 & $2.05,2.15$ each $\mathrm{m}$ & 42.7 \\
\hline 3 & $4.02 \mathrm{~m}$ & 68.2 & 68.3 & $3.95 \mathrm{~m}$ & 65.6 \\
\hline 4 & $1.57 \mathrm{~m}, 2.09$ br d (11.5) & 42.0 & 41.1 & $1.57 \mathrm{~m}, 1.80$ brd (11.5) & 36.7 \\
\hline 5 & - & 77.5 & 77.5 & - & 82.2 \\
\hline 6 & 3.46 br s & 76.6 & 76.4 & - & 214.8 \\
\hline 7 & $1.79,1.53 \mathrm{~m}$ & 35.2 & 36.4 & $2.79 \mathrm{t}(12.5), 2.15 \mathrm{~m}$ & 41.6 \\
\hline 8 & $1.78 \mathrm{~m}$ & 30.4 & 28.4 & $1.69 \mathrm{~m}$ & 41.5 \\
\hline 9 & $1.46 \mathrm{~m}$ & 53.0 & 49.5 & $1.47 \mathrm{~m}$ & 46.6 \\
\hline 10 & - & 41.0 & 40.0 & - & 46.7 \\
\hline 11 & $3.85 \mathrm{dt}(5.0,10.5)$ & 69.5 & 69.5 & $1.86,1.27$ each $\mathrm{m}$ & 23.2 \\
\hline 12 & $1.24 \mathrm{~m}, 2.28 \mathrm{dd}(12.5,5.0)$ & 52.8 & 50.5 & $1.99,1.32$ each $\mathrm{m}$ & 40.7 \\
\hline 13 & - & 44.3 & 43.1 & - & 43.6 \\
\hline 14 & $1.19 \mathrm{~m}$ & 57.6 & 59.3 & $1.17 \mathrm{~m}$ & 58.0 \\
\hline 15 & 1.39 brd (11.5), $1.18 \mathrm{~m}$ & 25.0 & 25.0 & $1.40 \mathrm{~d}(11.5), 1.18 \mathrm{~m}$ & 25.1 \\
\hline 16 & $1.54,1.30$ each $\mathrm{m}$ & 29.4 & 29.1 & $1.55,1.30$ each $\mathrm{m}$ & 29.2 \\
\hline 17 & $1.18 \mathrm{~m}$ & 56.6 & 58.3 & $1.18 \mathrm{~m}$ & 58.0 \\
\hline 18 & $0.74 \mathrm{~s}$ & 13.5 & 14.9 & $0.71 \mathrm{~s}$ & 12.5 \\
\hline 19 & $1.29 \mathrm{~s}$ & 17.6 & 20.3 & $0.78 \mathrm{~s}$ & 9.5 \\
\hline 20 & $1.40 \mathrm{~m}$ & 37.1 & 37.3 & $1.40 \mathrm{~m}$ & 37.1 \\
\hline 21 & $0.99 \mathrm{~d}(6.5)$ & 19.2 & 19.3 & $0.98 \mathrm{~d}(6.5)$ & 19.2 \\
\hline 22 & $1.05 \mathrm{~m}$ & 37.3 & 37.3 & $1.05 \mathrm{~m}$ & 36.7 \\
\hline 23 & $1.60 \mathrm{~m}$ & 25.3 & 25.3 & $1.61 \mathrm{~m}$ & 25.3 \\
\hline 24 & $1.17 \mathrm{~m}$ & 40.7 & 40.7 & $1.18 \mathrm{~m}$ & 40.7 \\
\hline 25 & $1.54 \mathrm{~m}$ & 29.2 & 29.2 & $1.54 \mathrm{~m}$ & 29.2 \\
\hline 26 & $0.89 \mathrm{~d}(6.5)$ & 22.9 & 23.0 & $0.89 \mathrm{~d}(6.5)$ & 23.0 \\
\hline 27 & 0.89 d (6.5) & 23.2 & 23.2 & $0.90 \mathrm{~d}(6.5)$ & 23.2 \\
\hline
\end{tabular}



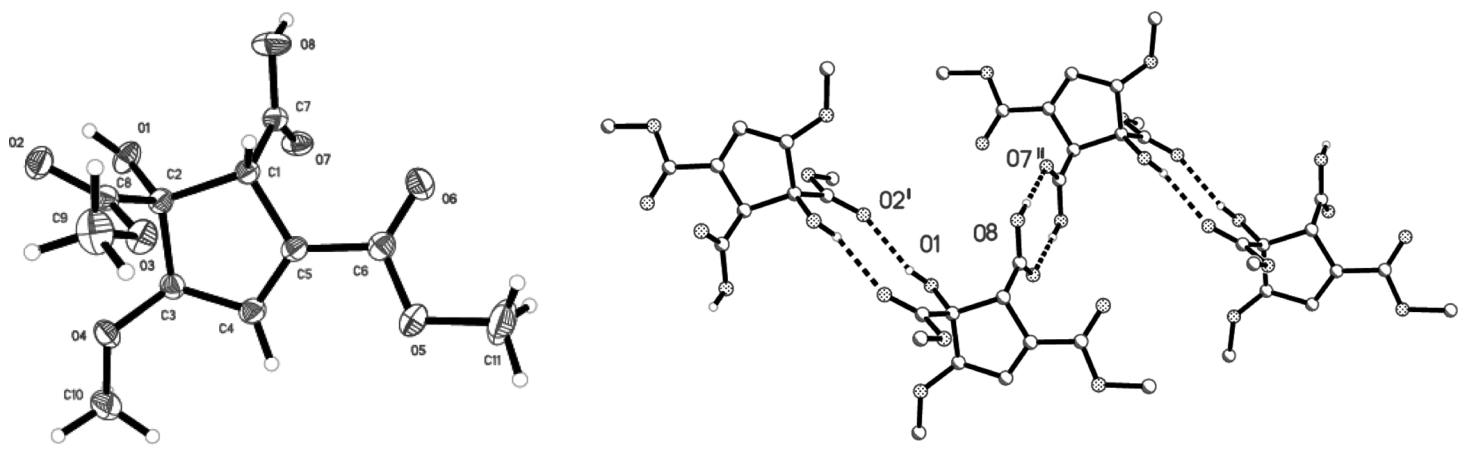

Fig. 3. Single-Crystal X-Ray Structure of $\mathbf{1}$

tween them are the downfield chemical shift of $3.5 \mathrm{ppm}$ C-9, and 2.3 ppm for $\mathrm{C}-12$, and the upfield shift to $\delta 3.85$ (H-11) compared to that of $\delta 4.14$ in $\mathbf{3}$, suggesting that 2 differs from 3 only at the probable stereochemistry of $\mathrm{C}_{11}-\mathrm{OH}$. This conclusion was supported by a comparision of their ${ }^{13} \mathrm{C}$ NMR and confirmed by the NOESY correlation between $\mathrm{H}$ 11 with H-19. Also, the H-11 $\beta$ configuration could be deduced by its coupling pattern ( $\mathrm{dt}, 5.0,10.5 \mathrm{~Hz})$ according to the literature. ${ }^{7)}$ Thus, compound 2 was determined to be cholestan-3 $\beta, 5 \alpha, 6 \beta, 11 \alpha$-tetrol, and called menellsteroid C.

Compound 7 was obtained as a white solid, with its molecular formula of $\mathrm{C}_{27} \mathrm{H}_{46} \mathrm{O}_{4}$ by its ESI-MS. The NMR data (Table 2) showed the typical signals of a polyoxygenated cholestan-type steroid: two tertiary methyls, three secondary methyls, and three oxygenated carbons. Its NMR data was closely similar to that of compound $5,{ }^{10)}$ including the coupling pattern of $\mathrm{H}-1$ (4.07, dd, 5.0, $11.5 \mathrm{~Hz})$, except for the appearance of an additional ketone signal at $\delta 214.8$ in 7, and the disappearance of the characteristic proton signal around $\delta 3.50$, which suggests the hydroxyl group at C-6 in compound $\mathbf{5}$ was oxygenated to a ketone in $\mathbf{7}$. All the NMR data was assigned by HSQC spectrum and was in agreement with references. ${ }^{10,11)}$ Thus, 7 was identified as $1 \beta, 3 \beta, 5 \alpha$-trihydroxycholestan-6-one. Since it was isolated as a natural product for the first time, we propose its trivial name menellsteroid D.

The other seven known compounds were identified as menellsteroid A (3), ${ }^{7,9)}$ cholestan-3 $\beta, 5 \alpha, 6 \beta$-triol (4), ${ }^{9)}$ cholestan- $1 \beta, 3 \beta, 5 \alpha, 6 \beta$-tetrol (5), ${ }^{10)}$ nephalsterol (6), ${ }^{12)}$ and cholestan-3 $\beta$-5-en-6-one (8), ${ }^{13)}$ and two briarane diterpenoids junceellolides B (9) and D (10), ${ }^{14)}$ by comparison of their NMR data with those of references.

Compound $\mathbf{1}$ is of special interest, as it is the first example with a highly oxygenated cyclopentene ring discovered from a gorgonian. Furthermore, $\mathbf{1}$ was a rarely reported and naturally occurring racemate. It was determined by the X-ray diffraction with a P-1 space group, and confirmed by its optical rotation value. It is structurally similar to $(+)$-kjellmanone (11) ${ }^{15,16)}$ a cyclopentenone derivative from the marine alga Sargassum kjellmanianum. Compound 7 was isolated as a natural product for the first time, and compounds $\mathbf{9}$ and $\mathbf{1 0}$ were the first two briarane diterpenoids found from Menella sp. to date.

Compounds $\mathbf{1}-\mathbf{3}$ and $\mathbf{7}$ were chosen to test the anti-inflammatory against lipopolysaccharide (LPS)-induced nitric oxide (NO) production in RAW264.7 macrophages. The results showed that $\mathbf{1}$ and $\mathbf{3}$ exhibited modest inhibition effects with $\mathrm{IC}_{50}$ of 71.3 and $33.9 \mu \mathrm{M}$, respectively, compared to the positive control aminoguanidine with $\mathrm{IC}_{50} 25.0 \mu \mathrm{M}$. In addition, compounds $\mathbf{1}-\mathbf{1 0}$ were evaluated by the anti-oxidant capacity in a radical 2, 2-diphenyl-(2,4,6-trinitrophenyl)hydrazyl (DPPH) free-radical assay, but no obvious scavenging effect was observed.

\section{Experimental}

General Experimental Procedures Melting points were determined on an X-5 digital micro melting point apparatus (Beijing Tech Instrument Co., Ltd., China) and are uncorrected. Optical rotations were recorded on a JASCO P-1020 digital polarimeter. IR spectra were measured on JASCO FT/IR-480 plus spectrometers. NMR spectra were recorded using Bruker $500 \mathrm{MHz}$ NMR spectrometers. HR-ESI-MS spectra were recorded on an Applied Biosystems Mariner 5140 spectrometer. The column chromatographies were applied on the Buchi Sepacore (C-615/605) system. All solvents used were of analytical grade (Tianjing Fuyu Chemical and Industry Factory, China). Silica gel and preparative TLC plates $(20 \times 20 \times 0.04 \mathrm{~cm})($ Qingdao Mar. Chem. Ind. Co., Ltd., China), Sephadex LH-20 gel (Pharmacia, Sweden) and $\mathrm{C}_{18}$ reverse-phased silica gel (150-200 mesh, Merck, Germany) were used for column chromatography.

Animal Material Fresh gorgonians was collected in April 2009 (7$10 \mathrm{~m}$ depth) off Meishan Island, Hainan province, China. The specimen was identified by Professor Hui Huang, the South China Sea Institute of Oceanology, Academia Sinica. A voucher specimen (No. M090402) was deposited in the Key Laboratory of Marine Bio-resources Sustainable Utilization, South China Sea Institute of Oceanology, Chinese Academy of Sciences, Guangzhou, P. R. China.

Extraction and Isolation The fresh gorgonian $(c a .5 \mathrm{~kg})$ were exhaustively extracted with $95 \%, 70 \% \mathrm{EtOH}$ and $\mathrm{CHCl}_{3}-\mathrm{MeOH}(1: 1)$ at room temperature, and the solvent was evaporated in vacuo. The residue was partitioned in $\mathrm{H}_{2} \mathrm{O}$ and extracted with petroleum ether (PE), EtOAc, and $n$-butanol, respectively, to provide the PE fraction $(16 \mathrm{~g})$, EtOAc fraction $(9.5 \mathrm{~g})$ and the $n$-butanol fraction $(11 \mathrm{~g})$. The EtOAc fraction was chromatographed on silica gel and eluted with PE-acetone $(50: 1)$, followed by a gradient of $\mathrm{CHCl}_{3}-\mathrm{MeOH}(100: 0,30: 1,10: 1,1: 1)$ to yield 8 fractions (Frs. A-G). Fr. B $(2.1 \mathrm{~g})$ was reseparated by Sephadex LH-20 (MeOH), followed by silica gel column chromatography (CC) and eluted with PE-acetone $(5: 3)$ to get 6 subfractions ( $\mathrm{Fr}$. Ba-f). A further isolation of $\mathrm{Fr}$. Bc yielded 10 $(4.6 \mathrm{mg})$ by preparative thin layer chromatography (p-TLC, two plates) with PE-EtOAc $(1: 1)$ as developer. The p-TLC (PE-acetone $5: 4$, one plate) of Fr. Bb provided $9(1.8 \mathrm{mg})$. Fr. E $(800 \mathrm{mg})$ was chromatographed by silica gel $\mathrm{CC}$ and eluted with PE-EtOAc $(1: 3)$, followed by a recrystallization $\left(\mathrm{CHCl}_{3}-\mathrm{MeOH} 1: 1\right)$ to obtain $1(13.7 \mathrm{mg})$.

The PE fraction was chromatographed on silica gel and eluted with a gradient of PE-EtOAc $(100: 0,50: 1,10: 1,2: 1,0: 1)$ to yield 14 fractions (Frs. 1-14). Fr. 12 (2.5 g) was subjected to silica gel CC with elution by PE-EtOAc ( $3: 1)$ to get 4 fractions (Frs. 12A-D), and twice to p-TLC of Fr. $12 \mathrm{C}(200 \mathrm{mg})\left(\mathrm{CHCl}_{3}\right.$-acetone $10: 1$ and PE-EtOAc $1: 1$ as developer, respectively) which yielded $8(2.2 \mathrm{mg})$. Fr. $14(4 \mathrm{~g})$ was resubjected to silica gel CC and eluted with a gradient of PE-EtOAc $(3: 1-1: 4)$ to 9 fractions (Frs. 14A-I). A purification by Sephadex LH-20 (MeOH) to Fr. $14 \mathrm{E}$ $(420 \mathrm{mg})$ produced $4(32.0 \mathrm{mg})$ and 4 other portions (Frs. $\left.14 \mathrm{E}_{1}-\mathrm{E}_{4}\right)$. Frs. $14 \mathrm{E}_{3}$ and $\mathrm{E}_{4}$ were subjected to $\mathrm{p}$-TLC $\left(\mathrm{CHCl}_{3}-\mathrm{EtOAc} 1: 5\right.$ and $\mathrm{PE}$-acetone $2: 3$, respectively) to obtain $7\left(3.9 \mathrm{mg}\right.$ ) (from Fr. $\left.14 \mathrm{E}_{3}\right)$, and $\mathbf{3}(16.1 \mathrm{mg})$ and $6(6.2 \mathrm{mg})$. Fr. 14C $(600 \mathrm{mg})$ was applied to silica gel CC and eluted with 
$\mathrm{CHCl}_{3}-\mathrm{MeOH}(10: 1)$ to yield 7 subfractions $(1-7)$. Fr. $14 \mathrm{C}_{6}(40 \mathrm{mg})$ was applied to p-TLC ( 3 plates) and developed by $\mathrm{CHCl}_{3}-\mathrm{EtOH}(5: 1)$ to get 2 (4.2 $\mathrm{mg})$ and $\mathbf{5}(8.5 \mathrm{mg})$.

Menellin A (1): Colorless quadrate crystal $\left(\mathrm{CHCl}_{3}-\mathrm{MeOH}\right) ; \mathrm{mp} 173.2$ $175.1^{\circ} \mathrm{C} ;[\alpha]_{\mathrm{D}}^{25}+0.0002(c=0.13, \mathrm{MeOH}) ; \mathrm{UV} \lambda_{\max }(\mathrm{MeOH}) \mathrm{nm}(\log \varepsilon)$ $222(3.98) \mathrm{nm}$; IR (KBr) $v_{\max } \mathrm{cm}^{-1}: 3485,3010,2955,1736,1706$ (br), 1645, 1436, 1258, 1146, 960; ${ }^{1} \mathrm{H}-$ and ${ }^{13} \mathrm{C}-\mathrm{NMR}\left(\mathrm{CD}_{3} \mathrm{OD}, 500 / 125 \mathrm{MHz}\right)$, see Table 1. ESI-MS $m / z 275[\mathrm{M}+\mathrm{H}]^{+}$; HR-ESI-MS $m / z 273.0618[\mathrm{M}-\mathrm{H}]^{-}$ (Calcd for $\mathrm{C}_{11} \mathrm{H}_{13} \mathrm{O}_{8}: 273.0616$ ).

Menellsteroid B (2): White powder; $[\alpha]_{\mathrm{D}}^{25}-18.5(c=0.12, \mathrm{MeOH})$; IR $(\mathrm{KBr}) v_{\max } \mathrm{cm}^{-1}: 3480,2905,2871,1458,1376,1200 ;{ }^{1} \mathrm{H}-$ and ${ }^{13} \mathrm{C}-\mathrm{NMR}$ $\left(\mathrm{CD}_{3} \mathrm{OD}, 500 / 125 \mathrm{MHz}\right)$, see Table 2. ESI-MS $m / z 459[\mathrm{M}+\mathrm{Na}]^{+}$; HR-ESIMS $m / z 437.3552[\mathrm{M}+\mathrm{H}]^{+}\left(\right.$Calcd for $\left.\mathrm{C}_{27} \mathrm{H}_{49} \mathrm{O}_{4}: 437.3553\right)$.

$1 \beta, 3 \beta, 5 \alpha$-Trihydroxycholestan-6-one (Proposed Menellsteroid D) (7): White solid; ${ }^{1} \mathrm{H}$ - and ${ }^{13} \mathrm{C}-\mathrm{NMR}\left(\mathrm{CD}_{3} \mathrm{OD}, 500 / 125 \mathrm{MHz}\right)$, see Table 2. ESI$\mathrm{MS} m / z 457[\mathrm{M}+\mathrm{Na}]^{+}$.

X-Ray Crystallographic Analysis of Menellin A (1) $\mathrm{C}_{11} \mathrm{H}_{14} \mathrm{O}_{8}$, $M=274.22$, triclinic, space group $P-1, a=7.9389(5) \AA, b=9.1825(6) \AA$, $c=9.7595(6) \AA . V=625.73(7) \AA^{3}, Z=2, D_{\text {calcd }}=1.455 \mathrm{Mg} / \mathrm{m}^{3}$, crystal dimensions $0.46 \times 0.43 \times 0.42 \mathrm{~mm}^{3}, \mu=0.126 \mathrm{~mm}^{-1}$. 5216 Reflections measured, 2659 reflections independent $\left(R_{\text {int }}=0.0154\right), R=0.0362, R w=0.1068$, X-ray diffraction experiments for this compound were carried out on a Bruker Smart $1000 \mathrm{CCD}$ diffractometer at $273 \mathrm{~K}$ using $\mathrm{MoK} \alpha$ radiation $(\lambda=$ $0.71070 \AA$ ). Absorption corrections were done by semi-empirical from equivalents. The structure was resolved using direct methods and refined with full-matrix least-squares on $F^{2}$. Crystallographic data for the structure of 1 have been deposited in the Cambridge Crystallographic Data Centre (deposition number CCDC 754564). Copies of the data can be obtained free of charge via www.ccdc.cam.ac.uk/conts/retrieving.html [or from the Cambridge Crystallographic Data Centre, 12 Union Road, Cambridge CB21EZ, U.K.; fax: t44 1223336033 or deposit@ccdc.cam.ac.uk].

Biological Assay The procedure reported by Yang et al. ${ }^{17)}$ was used for the measurement of anti-inflammatory inhibition against LPS-induced NO production in RAW 246.7 in macrophages, and the DPPH free-radical scavenging inhibitory activity was measured as described by Lee et $^{\text {al }}{ }^{18 \text { ) }}$

Acknowledgements This study was supported by Grants from the National Natural Science Foundation of China (Grant numbers: 40706046, 30973679, and 20902094), the National Key Basic Research Program of China (973)'s Project (2010CB833800), Knowledge Innovation Program of the Chinese Academy of Science (LYQY200703, SQ200904, and KSCX2-
YW-G-073), the Scientific Research Foundation for the Returned Overseas Chinese Scholars, State Education Ministry, and LMB (091002) Foundation. Our thanks are due to Mr. Jiang-Hui Tang for his assistance in collection of the gorgonian, Mr. Xiao-Long Feng (Sun Yat-Sen University) for the analysis of single-crystal X-ray diffraction, and Dr. Xiao-Qi Zhang (Jinan University) for his kind help in the measurement of physical data.

\section{References}

1) Zhang W., Guo Y. W., Chin. J. Nat. Med., 1, 69-75 (2003).

2) Berrue F., Kerr R. G., Nat. Prod. Rep., 26, 681-718 (2009).

3) Blunt J. W., Copp B. R., Hu W. P., Munro M. H. G., Northcote P. T., Prinsep M. R., Nat. Prod. Rep., 25, 35-94 (2008).

4) Blunt J. W., Copp B. R., Hu W. P., Munro M. H. G., Northcote P. T., Prinsep M. R., Nat. Prod. Rep., 26, 170-244 (2009).

5) Deng S. Z., Li F. Y., Peng S. S., Rao Z. G., Wu H. M., Xu J. H., Chin. J. Appl. Chem., 14, 80-82 (1997).

6) Zhang W., Guo Y. W., Mollo E., Cimino G., Helv. Chim. Acta, 87, 2919-2925 (2004)

7) Zhang W., Huang H., Ding Y., Gavagnin M., Mollo E., Cimino G., Guo Y. W., Helv. Chim. Acta, 89, 813-820 (2006).

8) Li L., Wang C. Y., Huang H., Mollo E., Cimino G., Guo Y. W., Helv. Chim. Acta, 91, 111-117 (2008).

9) Qiu Y. Q., Qi S. H., Zhang S., Yang J., Xiao Z. H., Pharmazie, 61, 645-647 (2006).

10) Kobayashi M., Hayashi T., Hayashi K., Tanabe M., Nakagawa T., Mitsuhashi H., Chem. Pharm. Bull., 31, 1848-1855 (1983).

11) Endo Y., Fukasawa H., Hashimoto Y., Shudo K., Chem. Pharm. Bull., 42, 462-469 (1994).

12) Wang G. Y. S., Li F. Y., Zeng L. M., Chem. J. Chin. Univ., 13, 623627 (1992).

13) Zhan Y. C., Chen L., Sun Y., Zhang N., Pei Y. H., J. Shenyang Pharm. Univ., 23, 358-360 (2006).

14) Shin J., Park M., Fenical W., Tetrahedron, 45, 1633-1638 (1989).

15) Nakayama M., Fukuoka Y., Nozaki H., Matsuo A., Hayashi S., Chem. Lett., 1980, 1243-1246 (1980).

16) Qin M. L., Li X. M., Yin S. W., Wang C. Y., Wang B. G., Marine Sci., 31, 47-50 (2007).

17) Yang Y. W., Zeng H. W., Liu X. H., Li S. M., Xu W., Sheng Y. H., Zhang C., Zhang W. D., J. Pharm. Pharmacol., 60, 937-941 (2008).

18) Lee Y. Y., Jang D. S., Jin J. L., Yun-Choi H. S., Planta Med., 71, $776-777$ (2005). 